\title{
The Simulation Damping of Power System Oscillation using Phase-Compensator and PID-Controller in Single-Machine Infinite-Bus
}

\author{
Agus Junaidi ${ }^{1}$, Rudi Salman ${ }^{2}$, Rahmaniar ${ }^{3}$, Abd. Hamid $\mathrm{K}^{4}$, Nizwardi Jalinus ${ }^{5}$, Ganefri $^{3}$ \\ \{agusjunaidi@unimed.ac.id ${ }^{1}$ \} \\ Department of Engineering, Universitas Negeri Medan ${ }^{1,2}$, Department of Engineering, Universitas \\ Pembangunan Panca Budi ${ }^{3,4}$, Faculty of Engineering Universitas Negeri Padang ${ }^{5,6}$
}

\begin{abstract}
The paper present the dynamic oscillation of the electric power system. The concept of system resilience that functions for machines that move normally and can return to a stable state after a disturbance occurs. Oscillation of changes in speed and oscillation changes in the electric power system occur due to disturbances. Disturbance in electricity causes an electric current that works on the system beyond the nominal current. The effect of the current disturbance will have an impact on changes in the current torque parameters that cause prime-over instability when the generator is operating. This instability will affect the rotor speed and the voltage emitted by the generator. Dynamic oscillation repair testing by applying phase compensation control and PID-Controller on the excitation system is done to see the response of speed and voltage response when the system is experiencing interference. Observation of system oscillation response using matlab simulation to see system performance. The simulation results show that dynamic stability improvement with phase compensation method can reduce oscillation speed and voltage within 6 seconds and the use of PID-controller can reduce the speed and voltage in 3 seconds. The phase compensation method and PIDcontroller applied to the excitation system can reduce the electric power system oscillation.
\end{abstract}

Keywords: Oscillation, Power System, Dynamic Stability, Phase-Compensator, PID

\section{Introduction}

The stability performance is an important factor in determining the quality of the SingleMachine Infinite-Bus (SMIB). In addition to stability performance, it also includes factors that affect the quality of the SMIB system, the system's ability to achieve a steady-state state of various kinds of disturbances that occur in SMIB system operations results in changes, especially changes in voltage response. If this situation is allowed to continue to occur, it will cause the SMIB performance to be disrupted and sometimes result in not being able to work normally after experiencing interference. To keep the single system running its operating point, it is necessary to analyze the SMIB system, especially its performance against interference. In the SMIB system, there are interruptions and there are minor disturbances. Many studies have been conducted to find oscillation damping techniques in electric power systems. The stability of the electric power system is done by tuning the Power System Stabilizer (Adi, 1994). The use of simulations is carried out in the field of short circuit 
analysis of the power interconnection system. Simulation experiments were carried out on a multi-engine electric power system. In the experiment, a short circuit simulation using software shows the results of the analysis applied to learn in higher education (Rahmaniar,2018). A study of damper oscillations of electric power systems was tested by applying optimal control and Power System Stabilizers (PSS) to electric power systems. Oscillation in the power system occurs due to a sudden disruption of the release of a large load or interference caused by a short circuit. The state of the system that experiences oscillation for a long time can cause interference to electrical equipment such as instrumentation, protection equipment and monitoring equipment at the electrical control centre. Experiments to test the system damping oscillation are applied in SMIB. SMIB as a plant is modelled with the state-space equation, and PSS and optimal control are applied to reduce oscillation. Matlab software is used as a tool to observe system performance. The test results show that the application of PSS and optimal control can reduce system oscillations (Agus,2018). Study of dynamic modelling and analysis applied to the SMIB system to test the dynamic stability of the power system. SMIB is modelled in nonlinear and linear models as a plan for implementing STATCOM using PID controllers. The analysis is done by looking at the eigen values of the simulation display (Ghazanfar,2009)

\section{Smib Dynamic Model}

The SMIB single machine of the power system (Praba,1994) shown in Fig. 1:

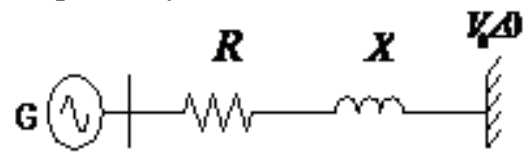

Fig. 1. Representation of SMIB Model

Mechanical torque Equations:

$$
\begin{aligned}
& \mathrm{Tm}=\mathrm{m} \cdot \mathrm{a} \\
& \mathrm{Tm}=\mathrm{m} \mathrm{d} \omega / \mathrm{dt}
\end{aligned}
$$

If the generator is loaded the mechanical torque will be affected by the electric torque:

$$
\begin{aligned}
& T_{m}-T_{e}=m \frac{d^{2} \delta}{d t^{2}} \\
& T_{m}-T_{e}=M \frac{d^{2} \delta}{d t^{2}} \Rightarrow \frac{T_{m}-T_{e}}{M}=\frac{d^{2} \delta}{d t^{2}}
\end{aligned}
$$

equation (2) can be arranged as a block diagram shown in Fig.2

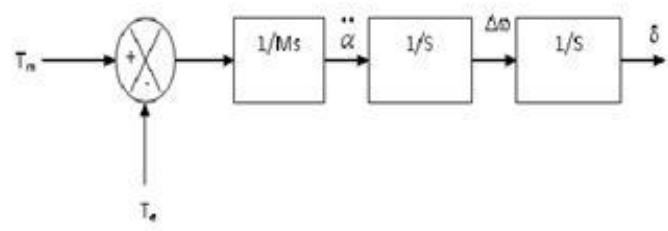

Fig. 2. generator is loaded the mechanical torque 
Damping system (D) as additional torque to stabilize the engine rotor simultaneously in this system, the damping provided by making a negative torque proportional to and phase with the rotor change $(\Delta \omega)$ :

$$
\begin{aligned}
& \mathrm{T}_{\mathrm{D}}=\mathrm{D} . \Delta \omega \\
& \Delta \omega=\frac{1}{M s}\left(\Delta T_{m}-\Delta T_{e}-D \Delta \omega\right)
\end{aligned}
$$

The angle position also affects the opponent's torque with the synchronization torque where:

$$
\mathrm{T}_{\mathrm{s}}=\mathrm{K}_{\mathrm{s}} \delta
$$

from equations (3) and (5), the block diagrams shown in figure 3:

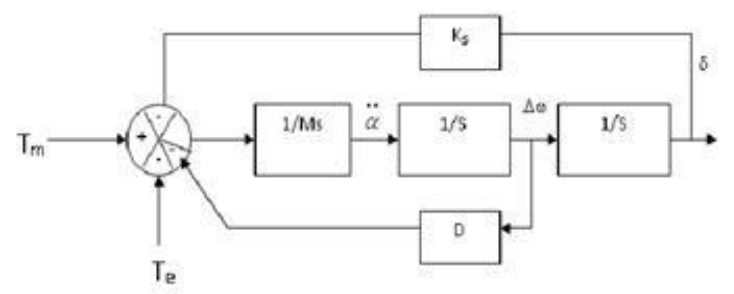

Fig. 3. Block diagram of Eq. (3) and Eq. (5) with TS and D

The effect of the K4 parameter on the rotor angle increase depicted in the block diagram is shown in Fig.4. The transfer function that describes changes in torque and rotor angle is formulated as:

$$
\frac{\Delta T_{E}}{\Delta \delta} \mid=-\frac{K_{2} K_{4} K_{3}}{1+s T^{\prime}{ }_{d o} K_{3}}
$$

from equations (6), the block diagrams shown in Fig.4:

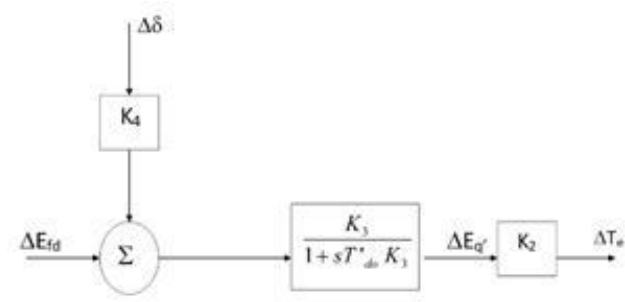

Fig. 4. The effect of the K4 parameter on the rotor angle

The transfer function that describes the voltage regulation system is:

$$
\frac{\Delta E_{f d}}{\Delta V_{t}}=\frac{K_{A}}{1+s T_{A}}
$$

For small fault analysis, the terminal voltage deviation can be connected to the angle change $\Delta \delta$ through the K5 factor whose value can change, then the change in the double flux $\triangle \mathrm{EQ}^{\prime}$ is connected via K6 whose value is always positive and decreases with the loading.

The block diagram of the SMIB electric power system (P.Anderson, 1977) can be shown in Fig. 5 


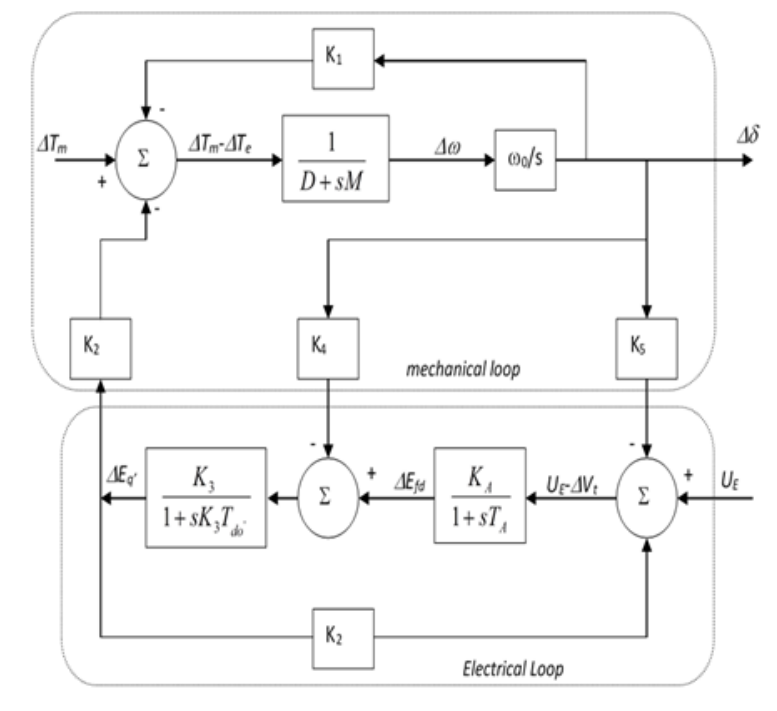

Fig. 5. Single-Machine Infinite-Bus Model

Fig. 5 shows The block diagram of the Single-Machine Infinite-Bus Model. Input torque is $\Delta \mathrm{Tm}-\Delta \mathrm{Te}$ as input and torque angle $\Delta \delta$ as output. The mechanical loop has two function blocks over from left to right, the first block is based on the torque balance equation, and the second block shows the angular and velocity relationships for the selected unit. In this block $M$ is the inertial constant, $D$ is the mechanical dampening coefficient and $2 \pi \mathrm{f}$ is the simultaneous speed.

The electric loop has additional $\mathrm{U}_{\mathrm{E}}$ control minus the additional terminal tension $\Delta \mathrm{Vt}$ as input, and the internal voltage $\left(\Delta \mathrm{Eq} \mathrm{q}^{\prime}\right)$ as the output multiplied by $\mathrm{K}_{2}$ as the electric torque $\Delta \mathrm{T}_{\mathrm{E}}$. The electric loop has two transfer function blocks from right to left the first block represents the voltage and excitation control system with the $\mathrm{T}_{\mathrm{A}}$ time constant and the gain $\mathrm{K}_{\mathrm{A}}$, the second block represents the function of the field circuit as the effect of the armature reaction, with the effective time constant of $\mathrm{T}_{3}{ }^{\prime} \mathrm{K}_{3}$ and the gain $\mathrm{K}_{3}$.

$\Delta \mathrm{Vt}$ consists of two components, $\mathrm{K}_{5} \Delta \delta$ is caused by changes in the torsion angle $\Delta \delta$ and $\mathrm{K}_{6} \Delta \mathrm{Eq}$ ' caused by changes in the tension in qEq'. $\Delta \mathrm{Vt}=\mathrm{Vt}-\mathrm{Vref}$, a negative sign is given to $\Delta \mathrm{Vt}$ because of negative feedback. Based on the block diagram, the stability of the power system is affected by the parameters $\mathrm{K}_{1}$ to $\mathrm{K}_{6} . \mathrm{K}_{1}, \mathrm{~K}_{2}, \mathrm{~K}_{3}, \mathrm{~K}_{4}$, and $\mathrm{K}_{6}$ are always positive, while $\mathrm{K}_{5}$ can change from positive to negative. The simulation design uses Matlab Simulink from the SMIB linear equation formed in the state variable equation (Katsuhiko,1994)

\section{Phase-Compensator And Pid-Controller}

\subsection{Phase Compensation Method}

A controller or commonly called PSS (Power System Stabilizer) is generally installed on the excitation system of speed response with the general form as stated by de Mello et al(1968): 


$$
G_{s}(s)=\left[\frac{K_{o} \tau_{o} s}{1+\tau_{o} s}\right]\left[\frac{1+a \tau s}{1+\tau s}\right]^{n}
$$

Previously we need to calculate the characteristic equation, undamped natural frequency and damping the inertial system factor:

$$
\begin{aligned}
& d(s)=s^{2}+2 \zeta_{x} \omega_{x}+\omega_{x}^{2} \\
& \omega_{x}=\sqrt{K_{1} \omega_{R} / 2 H} \\
& \zeta_{x}=D / 4 H \omega_{n}
\end{aligned}
$$

\subsection{PID-Controller}

PID controllers are very widely used in the industry for decades, the response is very fast but overshoot is also very large (L. Qi, 2010). Similarly, implementation on control Liquid level. Classic PID parameters usually remain during operation, consequently, the controller becomes inefficient to control the system if there is an unknown or unknown interference the environment around the system changes (Sinthipsomboon, 2011). So the PID control is not sufficiently adaptive (O.Wahyunggoro,2018) and also the determination of the PID parameter is also very difficult. One way to determine the PID parameters using the Ziegler-Nichols open loop method.

PID controllers are very widely used in electric power systems. The concept of the PID control system is shown in Fig. 6

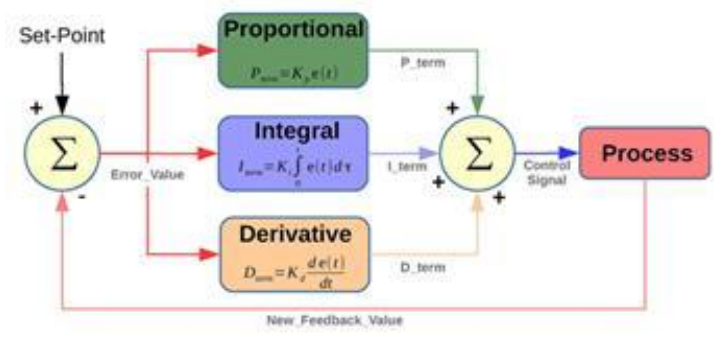

Fig. 6. The concept of the PID control system

The PID control process with the response is very fast but the overshoot is also very large. Classic PID parameters are usually fixed during operation, consequently, the controller becomes inefficient to control the system if there is an unknown interference or the environment around the system changes. open loop Ziegler-Nichols, Tuning is much better obtained by installing a model:

$$
P(s)=\frac{K}{1+s T} e^{-s T d e l}
$$

A simple way of tuning the PID control using an illustration of figure 9. Zero frequency retrieval from the Criteria gains process from the response of the steady-state value. Tdel time delay parameters of parameters to see Ziegler-Nichols step response with muffled oscillation calculations in closed loop systems (Desborough Honeywell, 2000) 


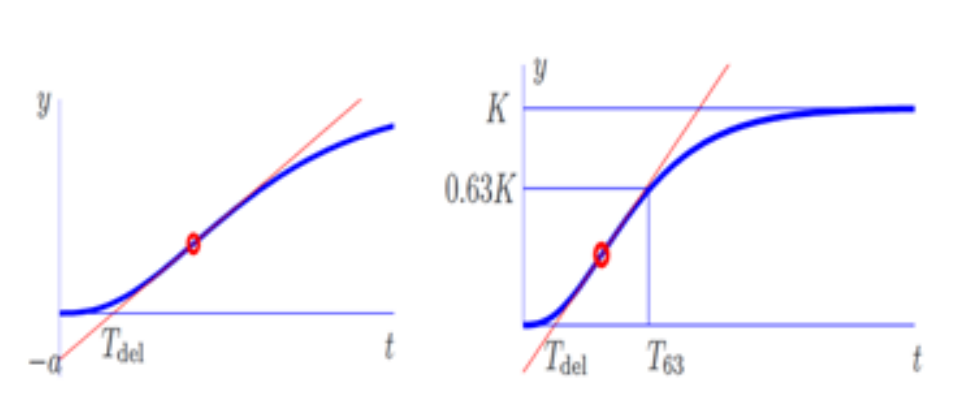

Fig. 7. The Characterization of the unit step response.

\section{Simulation Results}

A single synchronous generator model is shown in Fig. 8, The value of the system parameters that will be tested in the simulation from Fig. 8

Data Of The SMIB System:

$$
\begin{array}{ll}
\mathrm{K}_{1}=1.4479 & \mathrm{H}=2.37 ; 2 \mathrm{H}=4.74 \\
\mathrm{~K}_{2}=1.3174 & \mathrm{D}=2 \\
\mathrm{~K}_{3}=0.3072 & \omega_{\mathrm{R}}=314 \mathrm{rad} / \text { detik } \\
\mathrm{K}_{4}=1.8052 & \mathrm{Tdo}=5.9 \text { detik } \\
\mathrm{K}_{5}=0.0294 & \mathrm{~K}_{\mathrm{A}}=400 \\
\mathrm{~K}_{6}=0.5257 & \mathrm{~T}_{\mathrm{A}}=0.05 \text { detik }
\end{array}
$$

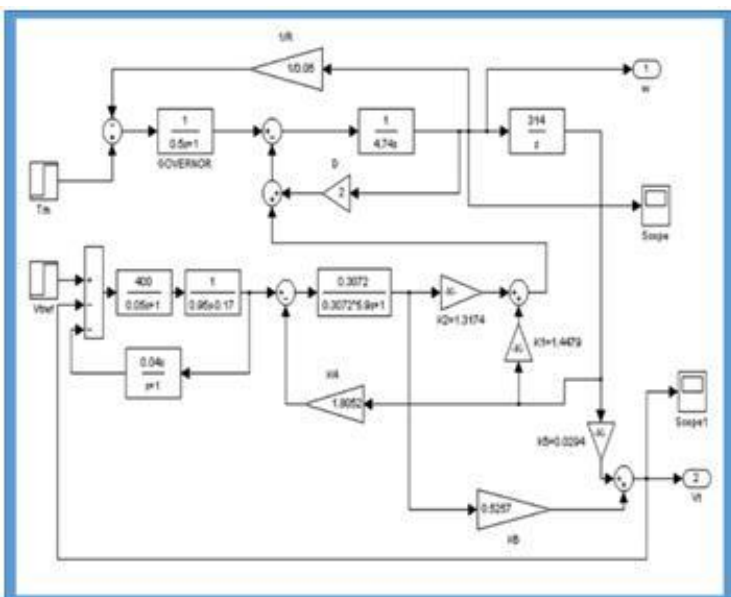

Fig. 8. Single-machine infinite-bus model (tested in the simulation)

\subsection{Simulation Result of the Generator in an Open Loop}


Simulation results, response speed and voltage of the generator in an open loop state (without control)are shown in Fig. 9 a and Fig b:

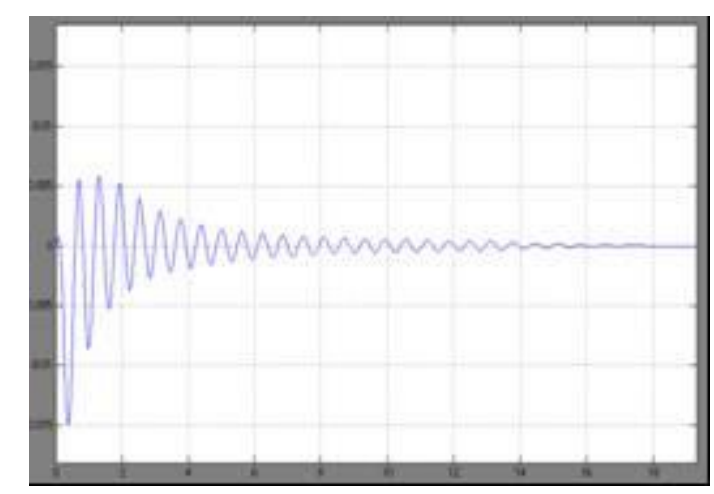

Fig. 9.a: a response speed of the Generator Systems in an open loop state (without control)

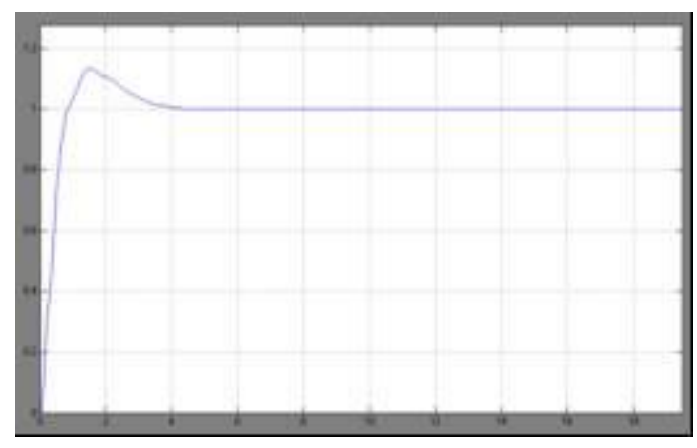

Fig. 9.b: A response voltage of the Generator Systems in an open loop state (without control) The eigen values of the system in the open loop condition
Eigenvalue
Damping
Freq. $(\mathbf{r a d} / \mathbf{s})$
$-4.92 \mathrm{e}-001+1.02 \mathrm{e}+001 \mathrm{i}$
4.82e-002
$1.02 \mathrm{e}+001$
$-4.92 \mathrm{e}-001-1.02 \mathrm{e}+001 \mathrm{i}$
$4.82 \mathrm{e}-002$
$1.02 \mathrm{e}+001$
$-1.20 \mathrm{e}+000+8.65 \mathrm{e}-001 \mathrm{i}$
$8.12 \mathrm{e}-001$
$1.48 \mathrm{e}+000$
$-1.20 \mathrm{e}+000-8.65 \mathrm{e}-001 \mathrm{i}$
$8.12 \mathrm{e}-001$
$1.48 \mathrm{e}+000$
$-1.93 e+000$
$1.00 \mathrm{e}+000$
$1.93 \mathrm{e}+000$
$-9.24 \mathrm{e}+000+1.49 \mathrm{e}+001 \mathrm{i}$
5.27e-001
$1.75 \mathrm{e}+001$
$-9.24 \mathrm{e}+000-1.49 \mathrm{e}+001 \mathrm{i}$
$5.27 \mathrm{e}-001$
$1.75 \mathrm{e}+001$

The low damping is $4.82 \mathrm{e}-002$ with the most dominant oscillation frequency being 10.2 $\mathrm{rad} / \mathrm{sec}$. The open loop system diagram is shown in Fig. 10 


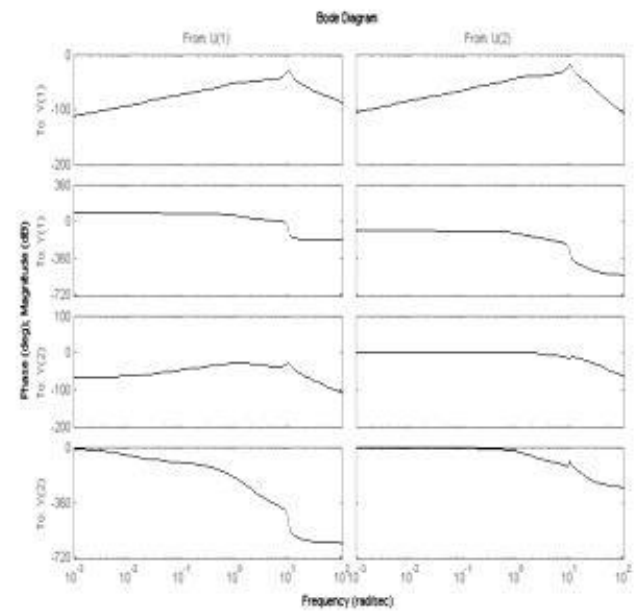

Fig.10. Open loop system bode diagram

\subsection{The Closed-Loop System with Phase Compensation Method}

From the results of the analysis using Eq. (8), eq. (10) and eq. (11), will be obtained:

$$
\begin{gathered}
G_{s}(s)=\left[\frac{20 s}{1+10 s}\right]\left[\frac{1+0.275 s}{1+0.035 s}\right]\left[\frac{1+0.275 s}{1+0.035 s}\right]\left[\frac{1+0.275 s}{1+0.035 s}\right] \\
\text { and, } \tau_{o}=10 ; \quad K_{o}=2
\end{gathered}
$$

The simulation of the controlled SMIB model with the three-level phase compensation method is shown in Fig. 11

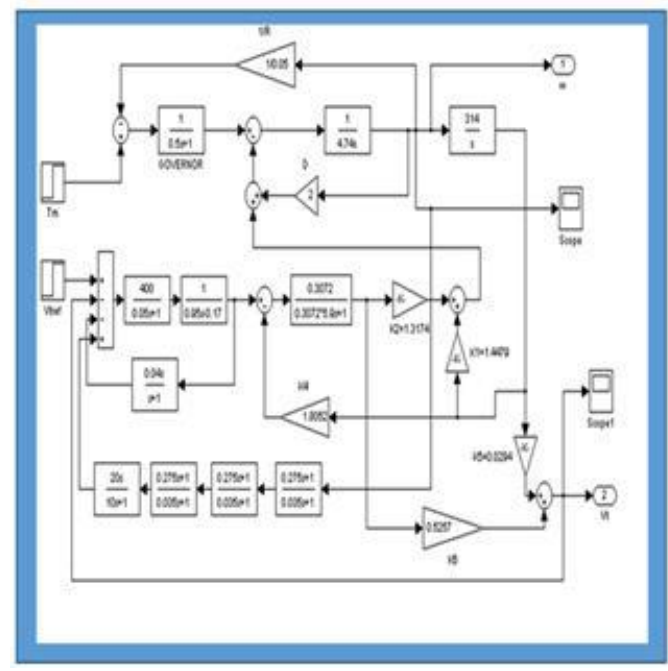


Fig.11. simulation of the controlled SMIB model with the three-level phase compensation methods From the simulation results of the SMIB model with a three-level phase compensation control, the eigen value is:

\begin{tabular}{|c|c|c|}
\hline Eigenvalue & Damping & \\
\hline$-1.00 \mathrm{e}-001$ & $1.00 \mathrm{e}+000$ & $1.00 \mathrm{e}-001$ \\
\hline$-1.20 \mathrm{e}+000+8.70 \mathrm{e}-001 \mathrm{i}$ & $8.09 \mathrm{e}-001$ & $1.48 \mathrm{e}+000$ \\
\hline$-1.20 \mathrm{e}+000-8.70 \mathrm{e}-001 \mathrm{i}$ & $8.09 \mathrm{e}-001$ & +000 \\
\hline$-1.55 e+000+8.16 e+000 i$ & $1.86 \mathrm{e}-001$ & +000 \\
\hline$-1.55 e+000-$ & 1.8 & 8.3 \\
\hline-1.93 & 1.0 & 000 \\
\hline$-3.89 e+000+2.11$ & 1.81 & +001 \\
\hline$-3.89 e+000-2.11 e+001 i$ & 1.8 & +001 \\
\hline$-1.19 e+001$ & 1.00 & $1.19 \mathrm{e}+001$ \\
\hline$-4.12 \mathrm{e}+001+1$ & -001 & $4.46 \mathrm{e}+001$ \\
\hline$-4.12 \mathrm{e}+001-1.70 \mathrm{e}+001 \mathrm{i}$ & $9.24 \mathrm{e}-001$ & $4.46 \mathrm{e}+001$ \\
\hline
\end{tabular}

From the results of the eigen values it can be seen that the lowest damping has increased from 4.82e-002 ( $\mathrm{f}=10.2 \mathrm{rad} / \mathrm{sec}$ ) in the open loop to $1.81 \mathrm{e}-001$ ( $\mathrm{f}=21.5 \mathrm{rad} / \mathrm{sec})$. And the bode diagram of the closed loop system is shown in Fig. 12.

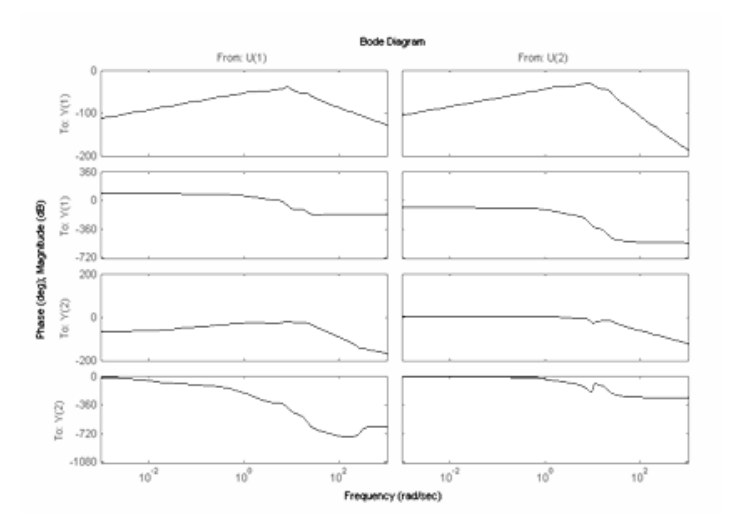

Fig.12. Closed loop system bode diagram using the three-level phase compensation method

Simulation results, response speed and voltage of the generator in a closed loop using the three-level phase compensation method are shown in Fig. 13.a and Fig 13.b:

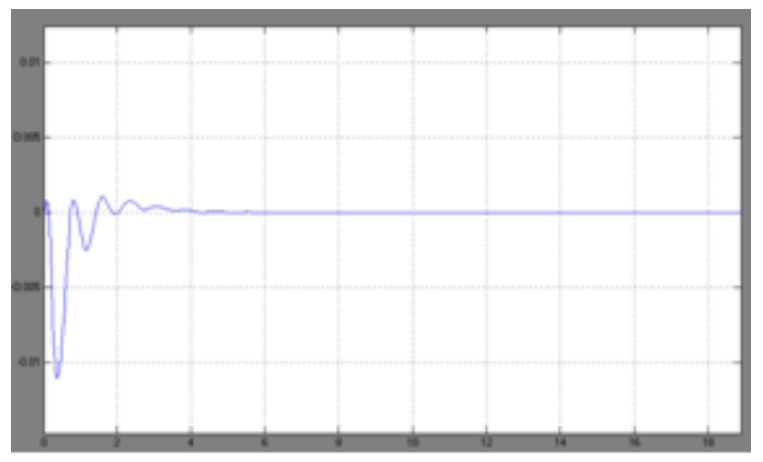


Fig.13.a. A response speed of the Generator Systems using the three-level phase compensation method

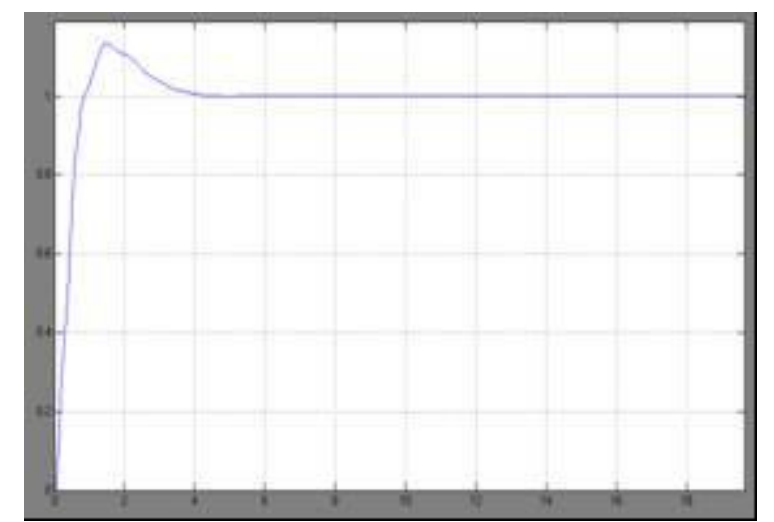

Fig.13.b. A response voltage of the Generator Systems in a closed loop using the three-level phase compensation method

\subsection{The Close Loop System: PID Controller Using Ultimate Sensitivity Method}

Tested with the $\mathrm{P}$ controller only, then the Kc gain is raised slowly to the stability limit. The proportional gain at that time is called Ko and the oscillation period is called To.

The optimum price of PID parameters is determined from the following table 1 :

Table 1. PID parameters

\begin{tabular}{ccc}
\hline Controller Type & Kc & TI \\
\hline P & 0.5 Ko & - \\
PI & $0.45 \mathrm{Ko}$ & $0.83 \mathrm{To}$ \\
PID & $0.6 \mathrm{Ko}$ & $0.5 \mathrm{To}$ \\
\hline
\end{tabular}

From the Fig. 8 of the SMIB system, it is tested by installing the $\mathrm{P}$ controller by increasing the gain at the stability limit. From the test with Matlab the response is obtained at the following stability limits, obtained Ko values $=300$ and To $=0.4$ seconds, Then the PID controller used is set as follows: $\mathrm{P}=0.5 \mathrm{Ko}=150 ; \mathrm{T}_{\mathrm{I}}=0.5 \mathrm{To}=0.2 ; \mathrm{TD}=0.125 \mathrm{To}=0.05$. These parameters are used as initial values. Then the settings are done manually to get the best response, The results are obtained: $P=100, T_{I}=0.2, T_{D}=0.05$, And the system with the PID controller installed on the excitation system of the speed response is shown in Fig. 14 


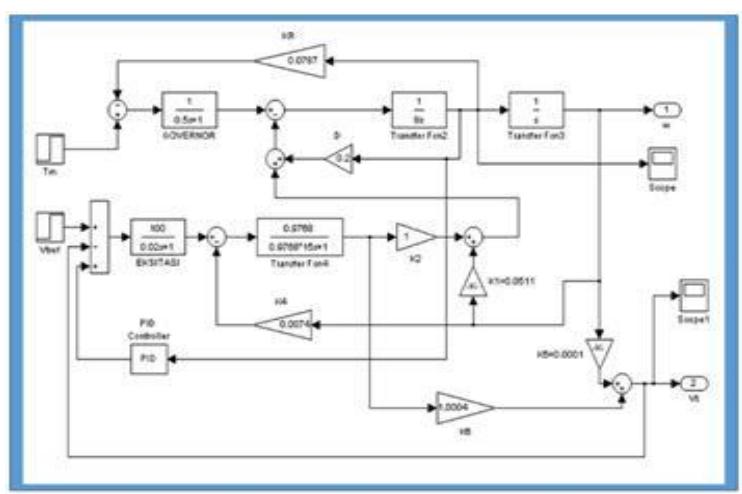

Fig.14. Closed Loop System SMIB using PID-Controller The system simulation response with PID control is shown in Fig. 15
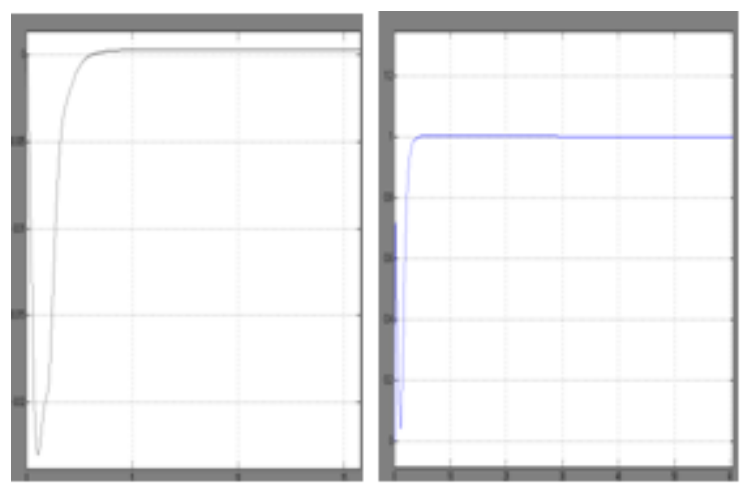

Fig.15. response speed and Voltage of the Generator Systems using PID-Controller

\section{Conclusions}

This paper discusses the improvement of oscillations in an electrical power system plan that is experiencing interference. The plan consists of a single generator connected to the bus called the SMIB model. SMIB is modelled in the state variable equation, then formed into the simulation block using Simulink. The trial is carried out in three stages, the plan is in an open loop state, the plan is controlled by the phase compensation model and the plan is controlled by the PID-Controller. The low damping is $4.82 \mathrm{e}-002$ with the most dominant oscillation frequency being $10.2 \mathrm{rad} / \mathrm{sec}$. The open loop system diagram. Oscillation improvements using phase compensation and PID-Controller from simulation results show system improvement. System oscillations can be significantly reduced. 


\section{Acknowledgement}

This research is a form of experimental research conducted with a lecturer in the Expertise Lecturer Group research in the department of electrical engineering, Faculty of Engineering of Medan State University, Collaboration with Faculty of Engineering Padang State University engineering and Department Of Electrical Engineering-Universitas Pembangunan Panca Budi Medan in an effort to synergize the improvement of the quality and quality of human resources among universities

\section{References}

[1] Adi Soeprijanto.: Metode Sederhana Penalaan power Sytems Stabilizer, Master of Engineering Thesis in ITB (1994)

[2] Agus Junaidi and Abd Hamid K.: Design of Simulation Product for Stability of Electric Power System Using Power System Stabilizer and Optimal Control, Journal of Physics: Conference Series Vol. 970, conference 1, IOP Publishing. (2018)

[3] Desborough Honeywell.: "PID Controller", Chapter 10, controllers utilize PID feedback. (2000)

[4] Ghazanfar Shahgholian, Pegah Shafaghi.: "Damping Power System Oscillations in SingleMachine Infinite-Bus Power System Using a STATCOM", 2009 Second International Conference on Computer and Electrical Engineering IEEE DOI 10.1109/ICCEE. (2009)

[5] Rahmaniar and Putri M.: Metode,"The Simulation Computer Based Learning (SCBL) for Short Circuit Multi-Machine Power System Analysis,"Journal of Physics: Conference Series Vol. 970, conference 1, IOP Publishing. (2018)

[6] Katsuhiko Ogata,.: ," Designing Linear Control Systems With Matlab” Prentice Hall, Ltd. (1994)

[7] L. Qi, F. Yanjun, S. Jizhong, and W. Ji.: "The Application of Fuzzy Control in Liquid Level system, "IEEE International Conference on Measuring Technology and Mechatronics Automation. (2010)

[8] P.M. Anderson, A.A Fouad..: “ Power System Kontrol and stability” The Iowa State University Press. (1977)

[9] Prabha Kundur.: ," Power System Stability and Control" Mv. Graw-hill. (1994)

[6] Sinthipsomboon K"A Hybrid of Fuzzy and Fuzzy self-tuning PID Controller for Servo Electrohydraulic System,"6th IEEE Conference on Industrial Electronics and Applications. (2011)

[6] Wahyunggoro and N. B. Saad.: Development of Fuzzy-Logic-Based Self Tuning PI Controller for Servomotor,"IEEE 10th Intl. Conf. on Control, Automation, Robotics and Vision Hanoi, Vietnam. (2008) 